\title{
A Novel Approach to Increase Robustness, Precision and High-Throughput Capacity of Single Cell Gel Electrophoresis
}

\author{
Juan C. Cassano ${ }^{1}$, Matthias Roesslein ${ }^{1}$, Rolf Kaufmann ${ }^{2,3}$, Thomas Luethi ${ }^{2}$, Oliver Schicht ${ }^{4}$, Peter Wick ${ }^{1}$ \\ and Cordula Hirsch ${ }^{1}$ \\ ${ }^{1}$ Particles-Biology Interactions Laboratory, Empa, Swiss Federal Laboratories for Materials Science and Technology, St. Gallen, Switzerland; ${ }^{2}$ Center \\ for X-ray Analytics, Empa, Swiss Federal Laboratories for Materials Science and Technology, Duebendorf, Switzerland; ${ }^{3}$ current address: Schaer Proton \\ AG, Flaach, Switzerland; ${ }^{4} 4 \mathrm{D}$ Lifetec AG, Cham, Switzerland
}

\begin{abstract}
Routine use of the single cell gel electrophoresis assay in medical diagnostics and biomonitoring is prevented by its high variability. Several factors have been identified and can be grouped into four main categories: 1) the biological sample, 2) the assay protocol, 3) the physical parameters during electrophoresis and 4) the analysis. Even though scientific knowledge on the assay variability is available, not much has been done so far to tackle the issues from the technological side. Therefore, this study addresses the question in how far the precise and accurate control over the physical parameters of electrophoresis is able to reduce the variability of single cell gel electrophoresis assay results. All four above-mentioned categories make up the overall assay variability. To resolve the contribution from a single category, the remaining three have to be kept as constant as possible. To achieve this, we generated a set of $\mathrm{x}$-ray treated control cells, worked according to a well-defined standard operating procedure, and one single operator performed the analysis. Thereby, variability resulting from the electrophoresis tank could be elucidated. We compared assay performance in two such tank systems: a newly developed electrophoresis tank that accurately controls voltage, temperature during the electrophoretic run and the homogeneity of the electric field, and a widely used commercially available standard platform tank.

Our results demonstrate that, irrespective of the cellular sample and its intrinsic biological variability, accurate control over physical parameters considerably increases repeatability, reproducibility and precision of single cell gel electrophoresis.
\end{abstract}

\section{Introduction}

Since its development in the 1980s (Ostling and Johanson, 1984; Singh et al., 1988), single cell gel electrophoresis (SCGE), otherwise known as the comet assay, has been applied to identify substances that cause DNA damage. It is an official test method for determining the genotoxic potential of any type of xenobiotic to which humans may be exposed (OECD, 2016) and has recently been used in medical settings such as the management of drug treatments in cancer patients (Apostolou et al., 2014).

The relatively simple method involves embedding the sample, i.e., a cell suspension retrieved from various sources such as cell cultures, liquid biopsies or dissociated tissue preparations, into low melting agarose (LMA) on glass slides. Cell lysis in a high salt and detergent-containing solution removes membranes and other cellular components, leaving behind only DNA at the position of the former cell nucleus. DNA unwinding and subsequent electrophoresis both take place under high $\mathrm{pH}(>13)$ conditions. Due to strand breakage, supercoiled loops of DNA are relaxed and extend during electrophoresis into the tail. Staining the resulting structures with a fluorescent dye reveals the typical "comet" like shape (Azqueta et al., 2019; Collins, 2004). More DNA damage increases the fraction of relaxed DNA loops and thereby the length and/or intensity of the comet tail. Thus, DNA damage can be quantified as tail length, $\%$ tail intensity (also called $\%$ tail DNA) or tail moment. The $\%$ tail intensity quantifies the fluorescence intensity of the tail relative to the overall intensity of the complete comet. The tail moment integrates the $\%$ tail intensity and the tail
Received June 25, 2019; Accepted August 28, 2019 ; Epub August 28, 2019; (C) The Authors, 2019.

ALTEX 37(1), 095-109. doi:10.14573/altex.1906252

Correspondence: Peter Wick, PhD and Cordula Hirsch, PhD

Particles-Biology Interactions Laboratory, Empa,

Swiss Federal Laboratories for Materials Science and Technology,

Lerchenfeldstrasse 5, 9014 St. Gallen, Switzerland

(peter.wick@empa.ch), (cordula.hirsch@empa.ch)
This is an Open Access article distributed under the terms of the Creative Commons Attribution 4.0 International license (http://creativecommons.org/licenses/by/4.0/) which permits unrestricted use, distribution and reproduction in any medium, provided the original work is appropriately cited. 


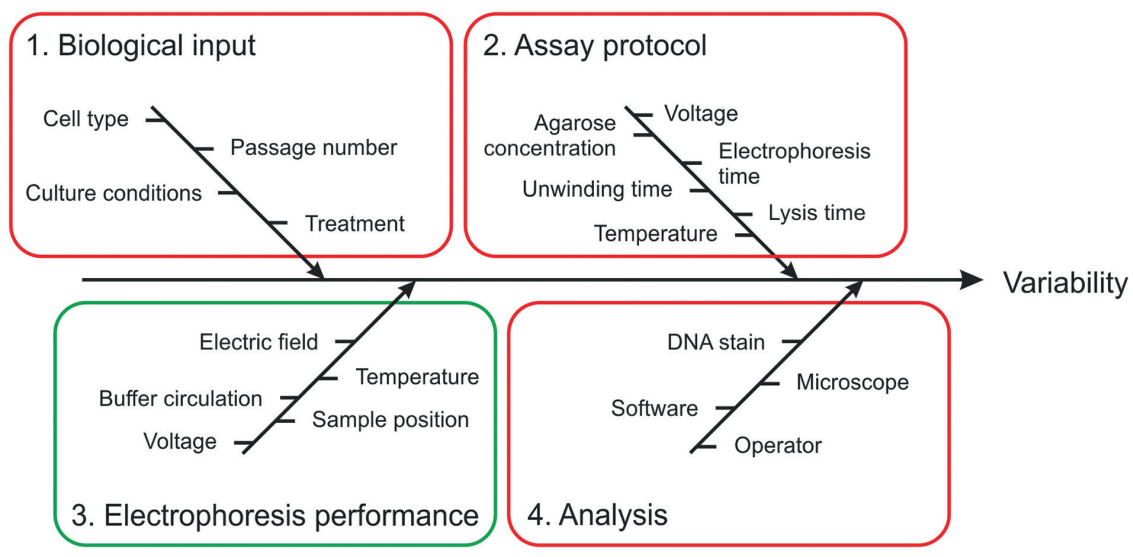

Fig. 1: Potential causes of variability in single cell gel electrophoresis (SCGE) results

Previously described sources of variability (Azqueta et al., 2019; Collins et al., 2014) are grouped into four categories and visualized in a cause-and-effect diagram. The impact of electrophoresis conditions on SCGE variability (depicted in green) was the focus of the study. To address this, sources of variability from the remaining groups, depicted in red, were kept as constant as possible.

length (Moller et al., 2014). The more prevalently used descriptor is the \% tail intensity, which is, furthermore, recommended by the OECD Test Guideline (TG) 489 (OECD, 2016) and references therein and is therefore applied throughout this study.

Although SCGE has great potential to be used in the diagnostic field (Anderson et al., 2014) as a powerful high-throughput (HT) solution, limitations due to SCGE variability and inconsistency still prevent diagnostic application. Over the years, researchers have elucidated numerous critical parameters that need to be standardized to increase comparability - or reduce variability of SCGE results (for comprehensive reviews see Azqueta et al., 2019; Collins et al., 2014 and references therein). These parameters can be categorized into four main groups (Fig. 1): 1) the biological input (i.e., the biological sample), 2) the assay protocol, 3 ) the performance of the electrophoretic run and 4) the analysis.

The variability of a biological sample is influenced by different factors. For example, the cell type, the passage number, and the culture and treatment conditions are of relevance for in vitro experiments, while the tissue or organism of origin are variability determinants of in vivo samples. Eventually, any sample will exhibit a certain intrinsic or natural variability on the single cell level that cannot be influenced by the experimenter. This biological spread is given by the respective sample and will, in the following, be referred to as "biological variability" or "comet distribution" (How do \% tail intensity values from one single cell in a sample differ from the next single cell of the same sample?).

The assay protocol defines how samples are processed from the cell harvest until the end of electrophoresis. The concentration of LMA, the lysis time, unwinding time, electrophoresis time, the voltage during electrophoresis as well as the temperature (during unwinding and electrophoresis) have been identified as critical parameters that influence SCGE results (Azqueta et al.,
2019; Collins et al., 2014; Ersson and Moller, 2011). However, the OECD TG 489 still allows for considerable degrees of freedom in several critical parameters. For example, the concentration of the LMA is not strictly specified but recommended to be between $0.5 \%$ and $1 \%$, but not below $0.45 \%$. Consequently, depending on the actual protocol applied by different labs, differences in SCGE results have to be expected, explaining, at least to a certain extent, the observed inter-laboratory variations (Forchhammer et al., 2012).

However, even when different labs have worked according to the same protocol, inter-laboratory variation has been reported (Forchhammer et al., 2012). This observation can be attributed to the performance of the electrophoretic run. The voltage, the homogeneity of the electric field, buffer circulation as well as temperature are known to be critical during electrophoresis (Brunborg et al., 2018). Since commercial SCGE platform tanks do not properly control all these parameters throughout the tank, the physical location of the sample within the electrophoresis tank will also influence the result. To overcome this issue, it is recommended to place slides randomly into the tank and to recirculate the electrophoresis buffer to decrease local variations in voltage (Collins et al., 2014; Gutzkow et al., 2013; OECD, 2016). Controlling the physical parameters of an electrophoretic run is thus essential to reduce inter- and intra-laboratory variability.

Finally, the analysis of the stained comets will influence the assay result. While different DNA-specific dyes have been shown to produce comparable results (Olive et al., 1992; Sirota et al., 2014), different analysis solutions lead to considerable variability (Forchhammer et al., 2010 and personal experience). Especially the operator performing the semi-automated scoring as well as the software solution chosen for analysis substantially impact the assay results. 
In more mathematical terms, we could say the observed variation in SCGE is the sum of variations introduced by 1) the biological sample, 2) the assay protocol, 3) the physical parameters during electrophoresis and 4) the analysis. Despite the fact that many of these critical factors have been known for years, from a technological point of view not much has been done to minimize them. Therefore, the aim of this study was to systematically determine the actual impact of accurate electrophoresis performance on the overall variation of SCGE.

To achieve this, we generated a batch of control cells and optimized the assay protocol that was then applied as a strict standard operating procedure (SOP). Furthermore, the same operator carried out image analysis according to a SOP. Therewith, all remaining sources of variability (1,2 and 4 above and illustrated in Fig. 1) were kept as constant as possible throughout the entire study. This allowed for a comprehensive assessment of a newly developed electrophoresis tank that precisely controls the relevant physical parameters of the assay and its comparison to a commercially available standard platform tank.

\section{Materials and methods}

\subsection{Chemicals}

All chemicals were purchased from Sigma-Aldrich $\mathrm{GmbH}$ (Buchs, Switzerland) unless otherwise specified. Water in all the experiments refers to ultrapure deionized water of $18.2 \mathrm{M} \Omega \mathrm{cm}$ (Millipore AG, Switzerland).

\subsection{Cell culture}

A549 lung alveolar carcinoma (ATCC ${ }^{\circledR}$ CCL-185) cells were grown in Roswell Park Memorial Institute (RPMI)-1640 medium supplemented with 10\% fetal calf serum (FCS), $0.2 \mathrm{mM}$ L-glutamine and $1 \mathrm{x}$ penicillin, streptomycin, neomycin (PSN) (Gibco, Thermo Fisher Scientific, France), termed as complete cell culture medium, under standard growth conditions (humidified atmosphere, $37^{\circ} \mathrm{C}, 5 \% \mathrm{CO}_{2}$ ). Cell viability and density were determined using the Trypan Blue exclusion method ( $0.4 \%$ Trypan blue solution) and a Neubauer counting chamber. At approximately $80-$ $90 \%$ confluency, cells were detached from the flask by trypsin/ethylenediaminetetraacetic acid (EDTA) and sub-cultured.

\subsection{Cell synchronization}

After $24 \mathrm{~h}$ in complete cell culture medium and under standard growth conditions, cells were starved of FCS for $48 \mathrm{~h}$ and subsequently treated with $5 \mu \mathrm{g} / \mathrm{ml}$ aphidicolin for $24 \mathrm{~h}$ to induce a G1/S-phase block (Pedrali-Noy et al., 1980). After that, aphidicolin was removed from the cell culture and cells were incubated for $24 \mathrm{~h}$ in complete cell culture medium to release them from the G1/S-phase block. Cells were then either processed for flow cytometric analysis or X-ray irradiation as described below.

\subsection{Flow cytometric analysis}

A549 cells were seeded into 6-well cell culture plates at a density of $1 \times 10^{5}$ cells per well in complete cell culture medium and underwent cell synchronization as described above. Thereafter, cells were harvested from the plate using trypsin/EDTA, resuspended in phosphate-buffered saline (PBS) and fixed with 70\% precooled ethanol for $2 \mathrm{~h}$ at $4^{\circ} \mathrm{C}$. After a washing step in PBS, cells were stained with propidium iodide (PI) staining solution $(10 \mu \mathrm{g} / \mathrm{ml}$ PI, $0.1 \%$ Triton X-100, $100 \mu \mathrm{g} / \mathrm{ml}$ DNase-free RNase $\mathrm{A}$ in PBS) for $30 \mathrm{~min}$ at room temperature (RT). Cell cycle was analyzed by flow cytometry using the Gallios ${ }^{\mathrm{TM}}$ flow cytometer and Kaluza acquisition software (Beckman Coulter, Krefeld, Germany). Upon excitation with a $488 \mathrm{~nm}$ laser, PI signals were collected in the FL3 channel (630 nm with $30 \mathrm{~nm}$ band pass width). Data were analyzed with Kaluza analysis software.

\subsection{DNA damage induction}

\section{Chemically}

A549 cells were seeded in complete cell culture medium into 6 -well plates at a density of $2.5 \times 10^{5}$ cells per well. After $24 \mathrm{~h}$ under standard growth conditions, cells were treated with 0,10 , 20 and $40 \mathrm{mM}$ ethyl methanesulfonate (EMS) in complete cell culture medium for $30 \mathrm{~min}$ under standard growth conditions. Subsequently, cells were trypsinized and collected for immediate DNA damage assessment by SCGE as described below.

\section{$X$-ray irradiation}

A549 cells were seeded in complete cell culture medium into T75 flasks at a density of $2 \times 10^{6}$ cells per flask. Cells were either treated $24 \mathrm{~h}$ after seeding (later referred to as unsynchronized samples) or underwent cell synchronization as described above (later referred to as synchronized samples).

In both cases, X-ray irradiation of A549 cells was performed using an industrial x-ray tube (Seifert Isovolt 420) operated at $130 \mathrm{kV}$ and $8 \mathrm{~mA}$. Cells were subjected to doses of $0,1,2,4$ and 8 gray (Gy) (unsynchronized) or $0,1,2,4,8$ and 12 Gy (synchronized) at a dose rate of roughly $0.5 \mathrm{~Gy} / \mathrm{min}$ at a distance of $31 \mathrm{~cm}$ and using a $6 \mathrm{~mm}$ aluminum filter. The dose was verified using a PTW Unidos Welbline dose rate meter (PTW-Freiburg, Germany). Immediately after irradiation, cells were trypsinized, collected in complete cell culture medium and diluted in an equal volume of freezing medium (30\% FCS, 20\% dimethyl sulfoxide (DMSO) in complete cell culture medium). Cell suspensions were aliquoted into cryotubes and frozen in CoolCell ${ }^{\circledR}$ cell freezing containers (Cryo Shop, München, Germany) that ensure a constant rate of $-1^{\circ} \mathrm{C} / \mathrm{min}$ in a $-80^{\circ} \mathrm{C}$ freezer for later use in SCGE. After $48 \mathrm{~h}$, these single-use aliquots were transferred to liquid nitrogen for long-term storage.

\subsection{SCGE}

Novel electrophoresis tank

Except for the comparative variability studies (see below), all SCGE assays were carried out using the 4D Lifetest ${ }^{\mathrm{TM}}$, hereafter referred to as "novel tank" (4D Lifetec AG, Cham, Switzerland). For technical details, refer to patent number PCT WO2016141495A3. Runs were carried out under constant circulation of the electrophoresis solution. Voltage and temperature measured by the "novel tank" were verified using externally calibrated measuring instruments during regular quality controls according to the user manual. The "novel tank" holds up to six 
Tab. 1: Optimization of SCGE parameter settings

\begin{tabular}{|l|l|l|l|l|l|l|l|}
\hline Parameters & $\begin{array}{l}\text { Initial } \\
\text { settings }\end{array}$ & \multicolumn{4}{l|}{ Single parameters varied } & \multicolumn{2}{l|}{$\begin{array}{l}\text { Optimized } \\
\text { settings }\end{array}$} \\
\hline & A & B & C & D & E & F & G \\
\hline LMA $(\%)^{1}$ & 0.4 & $\mathbf{0 . 6 8}$ & 0.4 & 0.4 & 0.4 & 0.4 & 0.4 \\
\hline T $\left({ }^{\circ} \mathrm{C}\right)$ & 4 & 4 & $\mathbf{1 5}$ & 4 & 4 & 4 & 4 \\
\hline $\mathrm{Ut}(\mathrm{min})$ & 20 & 20 & 20 & $\mathbf{4 0}$ & 20 & 20 & $\mathbf{4 0}$ \\
\hline $\mathrm{V}(\mathrm{V} / \mathrm{cm})$ & 1.0 & 1.0 & 1.0 & 1.0 & $\mathbf{1 . 1}$ & 1.0 & 1.1 \\
\hline Et $(\mathrm{min})$ & 20 & 20 & 20 & 20 & 20 & $\mathbf{3 0}$ & $\mathbf{3 0}$ \\
\hline
\end{tabular}

${ }^{1}$ To keep the volume ratio (cell suspension / LMA) and therewith the final cell number per spot constant, the concentration of the LMA stock solution was increased to $0.75 \%$ in setting $B$. Temperature $(T)$, Unwinding time (Ut), Voltage $(\mathrm{V})$ and Electrophoresis time (Et) were pre-set at and controlled by the 4D Lifetest ${ }^{\mathrm{TM}}$. Values that deviate from the initial settings (column A) are marked in bold.

4D Lifeplates ${ }^{\mathrm{TM}}$ (4D Lifetec AG, Cham, Switzerland) for sample mounting, which are available in 12-well and 96-well format. Therewith, 576 samples could be run simultaneously, offering considerable high-throughput (HT) capability. Magnets precisely position the plates inside the tank, allowing for one orientation only. Therefore, comets will extend towards the same direction on all plates and in every experiment.

The following parameters can be varied by the user and saved as templates:

- Temperature of the electrophoresis solution: $\mathrm{T}\left({ }^{\circ} \mathrm{C}\right)$; applied during unwinding and electrophoresis

- Unwinding time: Ut (min)

- Voltage: V(V/cm)

- Electrophoresis time: Et (min)

Run reports document the settings configured by the user and measure and record the respective values throughout the run. Any unexpected incident such as the accidental opening of the lid is documented.

\section{General protocol (optimized assay parameters)}

All A549 cell samples were diluted in complete cell culture medium to approximately $2 \times 10^{5}$ cells per mL and kept on ice. $160 \mu \mathrm{L}$ of $0.5 \%$ low melting agarose (LMA, Carl Roth, Karlsruhe, Germany) in PBS was aliquoted per microcentrifuge tube and kept liquid in a heat block set at $37^{\circ} \mathrm{C} .40 \mu \mathrm{L}$ of each cell suspension (containing $\sim 8000$ cells) was mixed with $160 \mu \mathrm{L}$ LMA, resulting in final concentrations of 40 cells per $\mu \mathrm{L}$ and $0.4 \%$ LMA. Directly after mixing, at least two spots per sample were transferred to a 4D Lifeplate $^{\mathrm{TM}}$. Spot sizes were found to be optimal with a volume of $5 \mu \mathrm{L}$ containing ca. 200 cells. To ensure even spacing, a 96-well format magnetic spotting guide (4D Lifegrid ${ }^{\mathrm{TM}}$ ) was used. Agarose was allowed to set for $1-2$ min at $4^{\circ} \mathrm{C}$ and samples were subsequently lyzed for $1 \mathrm{~h}$ at $4^{\circ} \mathrm{C}$ in freshly prepared lysis solution (2.5 M NaCl, $100 \mathrm{mM}$ EDTA, $10 \mathrm{mM}$ tris(hydroxymethyl) aminomethane (TRIS)-base, 1\% Na-laurylsarcosinate, 10\% DMSO, $1 \%$ Triton-X-100). During lysis, $1.5 \mathrm{~L}$ of freshly prepared electrophoresis solution $(0.3 \mathrm{M} \mathrm{NaOH}, 1 \mathrm{mM}$ EDTA, $\mathrm{pH} \geq 13)$ was placed into the "novel tank" and cooled to $4{ }^{\circ} \mathrm{C}$ according to the manufacturer's recommendations. After lysis, the 4D Lifeplate ${ }^{\mathrm{TM}}$ was placed into the "novel tank" via magnetic attachment. Samples then underwent unwinding at $4^{\circ} \mathrm{C}$ for $40 \mathrm{~min}$ and subsequent electrophoresis at $1.1 \mathrm{~V} / \mathrm{cm}$ for $30 \mathrm{~min}$. 4D Lifeplates ${ }^{\mathrm{TM}}$ were taken out of the "novel tank" after electrophoresis, excess liquid was carefully dripped off on a paper towel, and plates were submerged into neutralization buffer (0.4 M TRIS-base, $\mathrm{pH} 7.5)$ for $10 \mathrm{~min}$, rinsed with double distilled water $\left(\mathrm{ddH}_{2} \mathrm{O}\right)$, fixed in absolute ethanol for $10 \mathrm{~min}$ and dried over night at RT.

Variations of the protocol to elucidate optimal assay parameters The following five assay parameters were varied - one at a time - to elucidate the optimal settings for the x-ray treated A549 cell samples run in the "novel tank" (Tab. 1): 1) LMA, 2) temperature $(\mathrm{T}), 3)$ unwinding time (Ut), 4) voltage (V), 5) electrophoresis time (Et). Initial settings were adopted from an in-house protocol (Hirsch et al., 2011).

\section{Comparative variability studies}

To compare results from the "novel tank" to a widely used commercial platform tank system, the TREVIGEN ${ }^{\circledR}$ CometAssay $^{\circledR}$ ES II Electrophoresis System (AMS Biotechnology (Europe) Ltd, Massagno, Switzerland) was used. Synchronized x-ray treated A549 cells (4 Gy) and solutions as described above were used, and the optimized parameter settings (see above) were applied in both tank systems. The same number of spots was analyzed for both systems. Nine spots were distributed over six (4D Lifetest ${ }^{\mathrm{TM}}$ ) and 18 spots over three $\left(\right.$ Trevigen $\left.^{\circledR}\right)$ plates, respectively. Spot allocations on the plates as well as plate locations in the respective electrophoresis tanks are shown in Figure 2A,B.

In a second series of experiments, commercially available CometAssay ${ }^{\circledR}$ Control Cells, delivered with the standard platform tank together with the CometAssay ${ }^{\circledR} 96$ reagent kit (both AMS Biotechnology (Europe) Ltd, Massagno, Switzerland), were used according to the manufacturer's protocol and with all solutions delivered by the manufacturer in both tank systems. 
A

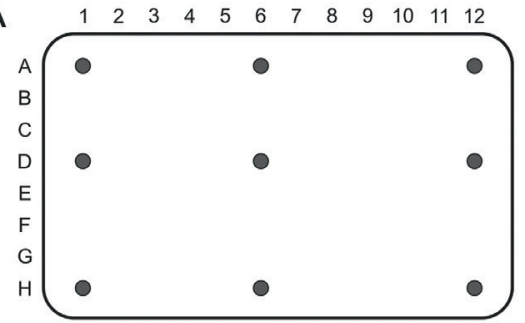

B

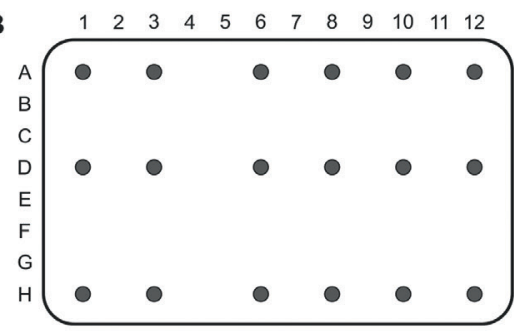

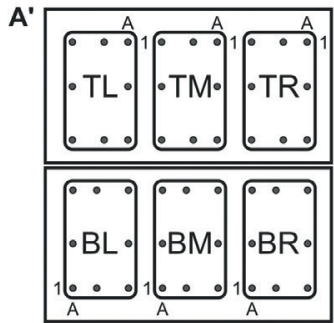

B'

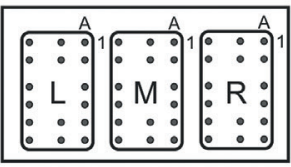

Fig. 2: Overview of the plate layout for the comparative variability study and a representative example of one spot A) Spot allocations of the nine spots on each of the six 96-well format plates of the "novel tank". A') Plate location and label in the "novel tank". B) Spot allocation of the 18 spots on each of the three commercial plates. B') Plate location and label in the standard "platform tank". TL, top left; $T M$, top middle; TR, top right; L, left; $M$, middle; $R$, right. C) One spot of an 8 Gy treated sample run in the "novel tank" stained with SYBR ${ }^{\circledR}$ Gold. D) Magnification from $(C)$ showing exemplarily the quantification heat map of one comet as visualized by Comet Assay IV software.
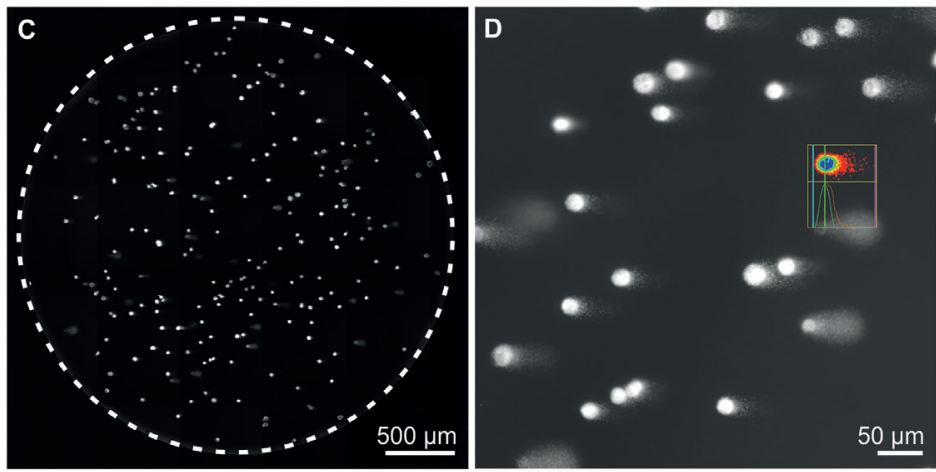

\subsection{Staining, imaging and DNA damage quantification} DNA was stained with 1 x $\mathrm{SYBR}^{\circledR}$ Gold nucleic acid stain (Molecular Probes, Thermo Fisher Scientific) solution in water for $20 \mathrm{~min}$ at RT in the dark. After two washing steps in $\mathrm{ddH}_{2} \mathrm{O}$ (10 min each), samples were dried for $2 \mathrm{~h}$ at $37^{\circ} \mathrm{C}$. Samples were re-hydrated with a drop of $\mathrm{ddH}_{2} \mathrm{O}$, covered with coverslips and imaged using a Zeiss Axio Imager microscope, a 10x objective and Zen software (Carl Zeiss, Jena, Germany). 35 overlapping tiled images were taken, creating a mosaic of the whole spot as shown in Figure 2C. Each separate image tile was converted into a greyscale tiff file for analysis with Comet Assay IV software (Perceptive Instruments; Fig. 2D). DNA damage was quantified using the $\%$ tail intensity values that were retrieved from the Comet Assay IV software upon accurate manual adjustment of the center line to the geometric center of the comet head region.

\subsection{Data processing and statistics}

If not stated otherwise, a minimum of three experiments was performed, each with two technical replicates (later on referred to as "spots"). In each spot, 100 comets were analyzed, resulting in a total of 200 comets per sample per experiment. For each spot, mean values and corresponding standard deviations from 100 comets were calculated (spot means). Subsequently, the mean of the two spot means was calculated for each experiment (experimental mean). Finally, the mean value and the corresponding standard deviation of all experimental means was calculated (overall mean). The coefficient of variance (CV (\%)) is given as a measure of variability and was calculated from (a) experimental means (generally three independently generated values) and (b) spot means (generally six values resulting from three independent experiments).

If not otherwise stated, box plots are generated from $\%$ tail intensity values of 100 single comets contained in one spot. The centerline represents the median and the cross represents the mean of the distribution. The box covers the inner quartile range, whiskers the minimum and maximum values, and dots represent outliers of the distribution, which are defined as 1.5 times the inner quartile range. 


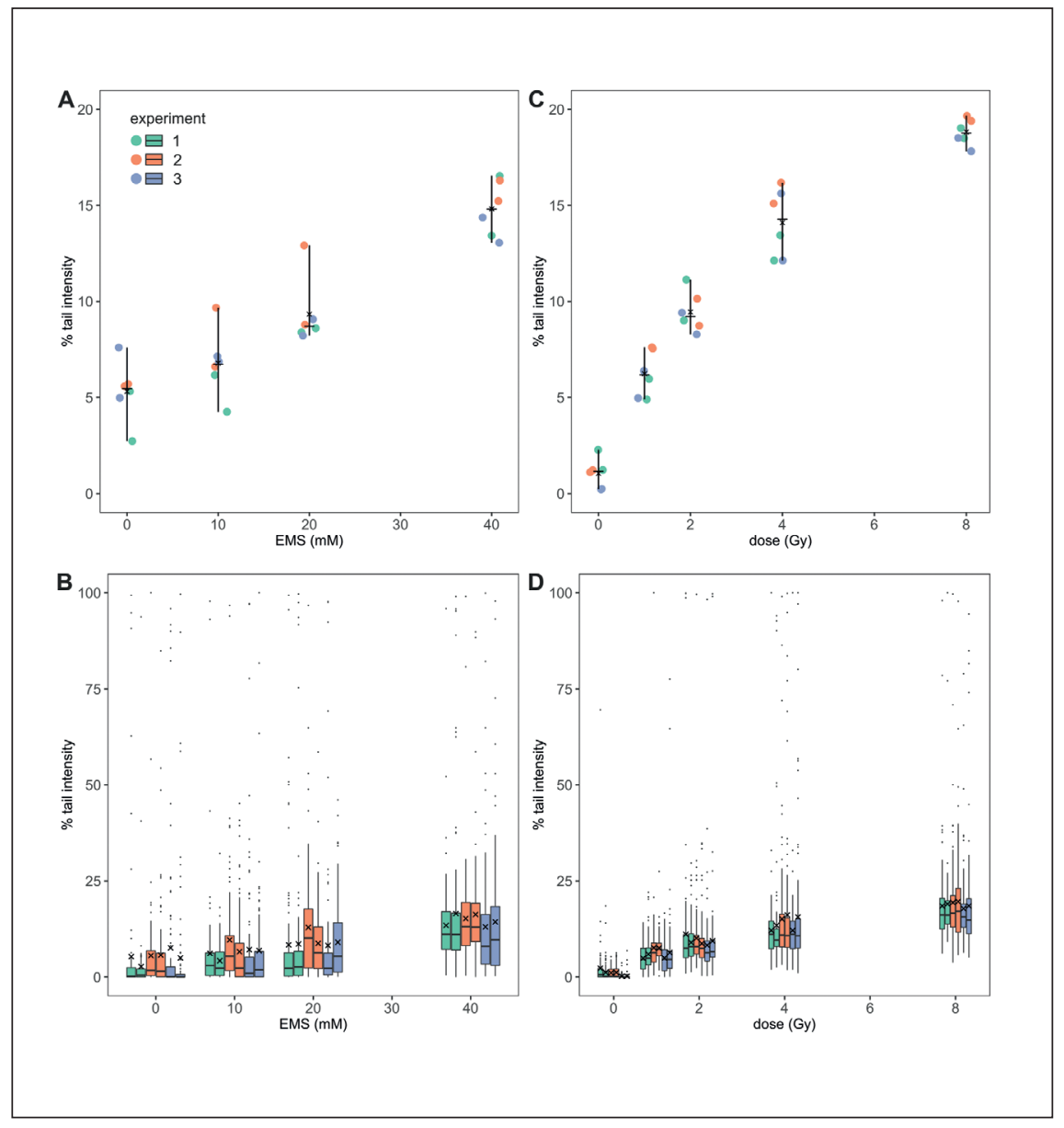

Fig. 3: Generating the biological control sample: Treatment of A549 cells with EMS or $x$-rays induces DNA damage in a dose-dependent manner

A549 cells were exposed to increasing doses of ethyl methanesulfonate (EMS) for 30 minutes $(A$ and $B)$ or $x$-ray irradiation $(C$ and $D)$ at the indicated doses. Three independent experiments with two technical replicates (=spots) each were performed. Results from the same experiments are shown in the same color. Each dot in A) and C) represents the mean \% tail intensity of 100 comets analyzed from one spot. The mean of all spot means is depicted as a cross $(\mathrm{x})$, the median as a horizontal line (-), and the spread of all spot means (minimum to maximum value) as a vertical line (I). The intrinsic biological variability (=comet distribution) of each spot is shown in $B$ ) and D) as box plots. As detailed in the materials and methods section, boxes cover the inner quartile range, whiskers show minimum and maximum values, outliers are indicated by black dots, and mean and median values are depicted as (x) and (-), respectively. The color code shown in $A$ applies to all graphs (A to D). Effects shown in A) and C) positively correlate with increasing treatment concentrations with correlation coefficients of $0.94(\mathrm{~A})$ and $0.92(\mathrm{~B})$.
Microsoft Excel (2016) as well as R (R Core Team, 2018) and ggplot $2^{1}$ were used for figures and statistical calculations. Statistical differences were assessed by Student's t-test in Excel and R (see supplementary file $2^{2}$ for further details). F-test analysis was performed in Excel to test for differences in the variances of two populations. Correlation analysis was performed in $\mathrm{R}$ using the core function cor (R Core Team, 2018).

\section{Results}

The routine assessment of DNA damage in clinical settings or biomonitoring requires a consistent workflow including standardized equipment for precise measurements as well as SOPs for sample preparation and analysis. Furthermore, HT capability to handle respective sample numbers is indispensable.

In this study, we focused on the impact of the physical parameters during electrophoresis on the precision of SCGE. For this purpose, we kept three of four known sources of SCGE variability constant (summarized in Fig. 1) and contrasted the perfor- mance of two electrophoresis systems. Experimentally, this necessitated 1) the generation of control cells as a continuous and unchanged biological sample and 2) the optimization of the assay protocol. Both were prerequisites for 3) the comprehensive assessment of a newly developed electrophoresis tank in comparison to a commercially available standard platform tank. For consistency throughout the study, one single operator performed the image analysis according to a SOP. The optimization of image analysis is a topic in itself, which was out of the scope of this study and is thus not further addressed experimentally here.

\subsection{Generation of control cells}

In a first attempt, we took the recommendations of the OECD TG 489 into account and "established experimental competency in SCGE" (OECD, 2016) with the "novel tank". To be able to match the data sets with previous results from our lab (May et al., 2018), we used the lung epithelial cell line A549 and the known alkylating agent ethyl methanesulfonate (EMS).

In three independent experiments, with individual cell passages and separately prepared EMS dilutions, we obtained reproduc-

\footnotetext{
1 https://ggplot2.tidyverse.org/

2 doi:10.14573/altex.1906252s2
} 
ibly low values in untreated control samples, showing on average $5 \%$ tail intensity. Furthermore, cells repeatedly responded in a dose-dependent manner to treatment with increasing EMS concentrations $(10,20$ and $40 \mathrm{mM})$, resulting in up to $15 \%$ tail intensity at $40 \mathrm{mM}$ (Fig. 3A).

Each box plot shown in Figure 3B comprises 100 individual comets from a single spot and therefore depicts the intrinsic biological variability of that particular sample (hereafter also called "comet distribution"; terms will be used interchangeably). Comparing the comet distributions (i.e., box sizes) of all six spots of one treatment condition (three experiments, two spots each) revealed differences from one experiment to the other (Fig. 3B). Nevertheless, mean values of the individual comet distributions (spots) as well as experimental means (as defined in the materials and methods section) were well reproducible with $\mathrm{CV}$ values of $9 \%$ to $27 \%$ (comparing the means of all individual spots; Fig. $\mathrm{S} \mathrm{A}^{3}$ ).

As a second DNA damaging treatment, we used x-ray irradiation since the DNA damage is expected to be more homogeneous compared to chemically induced damage (Collins et al., 2014). Furthermore, we wanted to eliminate confounding factors such as cell passage number or growth conditions that might influence assay results. Therefore, A549 cells were exposed to defined $x$-ray doses $(0,1,2,4$ and 8 Gy). For each dose, single use aliquots were frozen. Three experiments were run on different days using one set ( 0 to $8 \mathrm{~Gy}$ ) of frozen samples each. Mean values of all spots from all experiments are shown in Figure 3C. With an average tail intensity of $1 \%$, DNA damage levels in untreated samples were low and increased dose-dependently upon $\mathrm{x}$-ray irradiation. Comet distributions were comparable from one experiment to the other as well as from one spot to the other as indicated by boxes of similar size and mean as well as median tail intensity values (Fig. 3D). One exception was the 0 Gy sample, where DNA damage levels were lower in the third experiment. This was also reflected in the CV values of all spot means, which ranged from $3 \%$ to $17.5 \%$ in 8 Gy to 1 Gy treated samples, respectively, and $66 \%$ in the 0 Gy sample (Fig. $\left.\mathrm{S} 1 \mathrm{~B}^{3}\right)$. However, control charting over a period of 10 months confirmed that this reduction was a unique outlier (data not shown) and will thus not be discussed in more detail here.

These results confirmed the general proficiency of the laboratory and the equipment to perform SCGE on A549 cells. However, treatment of A549 cells with $20 \mathrm{mM}$ EMS has been reported to induce tail intensity values of 40 to $50 \%$ (May et al., 2018), rather than $10 \%$ (Fig. $3 \mathrm{~A}$ ). This discrepancy could be due to the experimental conditions during SCGE (including parameters such as the temperature during the electrophoretic run) or to differences in the cell culture. Furthermore, with a maximum DNA damage level of $19 \%$ induced by an x-ray dose of $8 \mathrm{~Gy}$, the theoretical dynamic range of SCGE from 0 to $100 \%$ tail intensity had not been reached by far. This, however, would be the pre-requisite to demonstrate reproducibility and precision for a variety of samples at all levels of DNA damage. To extend the dynamic range of DNA damage detection, two aspects were examined further: the cell sample itself and parameters of assay performance.

\section{Synchronization of A549 cells}

Typically, cells in culture grow asynchronously with subpopulations of cells being in distinct stages of the cell cycle $\left(\mathrm{G}_{0}, \mathrm{G}_{1}\right.$, $\left.\mathrm{S}, \mathrm{G}_{2}, \mathrm{M}\right)$. Synchronization of different cell types and subsequent analysis of DNA damage in untreated cells showed that the amount of basal DNA damage increases from $\mathrm{G}_{1}$ - to S-phase and declines again in $\mathrm{G}_{2}$-phase (McArt et al., 2010; Potter et al., 2002). The susceptibility of cells towards certain DNA damaging agents has also been shown to correlate with cell cycle phases. While effects of $\gamma$-irradiation or $\mathrm{H}_{2} \mathrm{O}_{2}$ were independent of the cell cycle phase, doxorubicin (Potter et al., 2002) and x-ray treatment (McArt et al., 2010) induced greater damage in $\mathrm{G}_{2}$ and $\mathrm{S}$ phase, respectively. Thus, based on existing protocols (PedraliNoy et al., 1980), we synchronized our cells in S-phase before subjecting them to x-ray irradiation. Additionally, the x-ray dose was increased to a maximum of 12 Gy to increase the dynamic range of detectable DNA damage. Generating a more homogenous cell culture in terms of susceptibility of individual cells to DNA damage, we also expected a reduction in the biological variability of the samples upon synchronization.

Flow cytometric analysis confirmed a doubling of the S-phase population from $16 \%$ in unsynchronized to $34 \%$ in synchronized cultures (Fig. S2 ${ }^{3}$, Tab. S1 ${ }^{3}$ ). \% tail intensity values in untreated synchronized samples increased by a factor of three compared to unsynchronized values and reached on average $4.7 \%$. This increase is comparable to results obtained in HeLa cells (McArt et al., 2010). Similarly, x-ray treatment was approximately twice as efficient towards synchronized cells (Fig. 4A), confirming a higher susceptibility of these A549 cultures.

However, cell synchronization did not have a positive effect on the biological variability within each sample. Figure 4B compares three randomly selected spots of both 4 Gy treated samples, revealing rather a greater spread of the comet distribution after cell synchronization. The complete data set of the full dose-response curve can be found in Figure S3A, $\mathrm{B}^{3}$. Irrespective of this increase in biological variability, the reproducibility of experimental as well as spot means remained comparable between synchronized and unsynchronized samples. For all treatment conditions analyzed, $\mathrm{CV}$ values were below $10 \%$, indicating consistently good reproducibility (Fig. 4C, Fig. S3C 3 ) (Collins et al., 2014). Even though synchronized A549 cultures proved to be more susceptible to x-ray induced DNA damage, $\%$ tail intensity values still did not exceed $35 \%$ at the highest dose of 12 Gy (Fig. 4A). Such high doses of irradiation are expected to be lethal and have been shown to induce higher levels of DNA damage (Enciso et al., 2018), which are at least partially due to DNA disintegration upon cell death (Henderson et al., 1998). Together with the observation that indeed no viable (i.e., proliferative) cells remained in the 12 Gy synchronized sample (Fig. $\mathrm{S}^{3}$ ), we concluded that in the next step parameters of as-

3 doi:10.14573/altex.1906252s1 

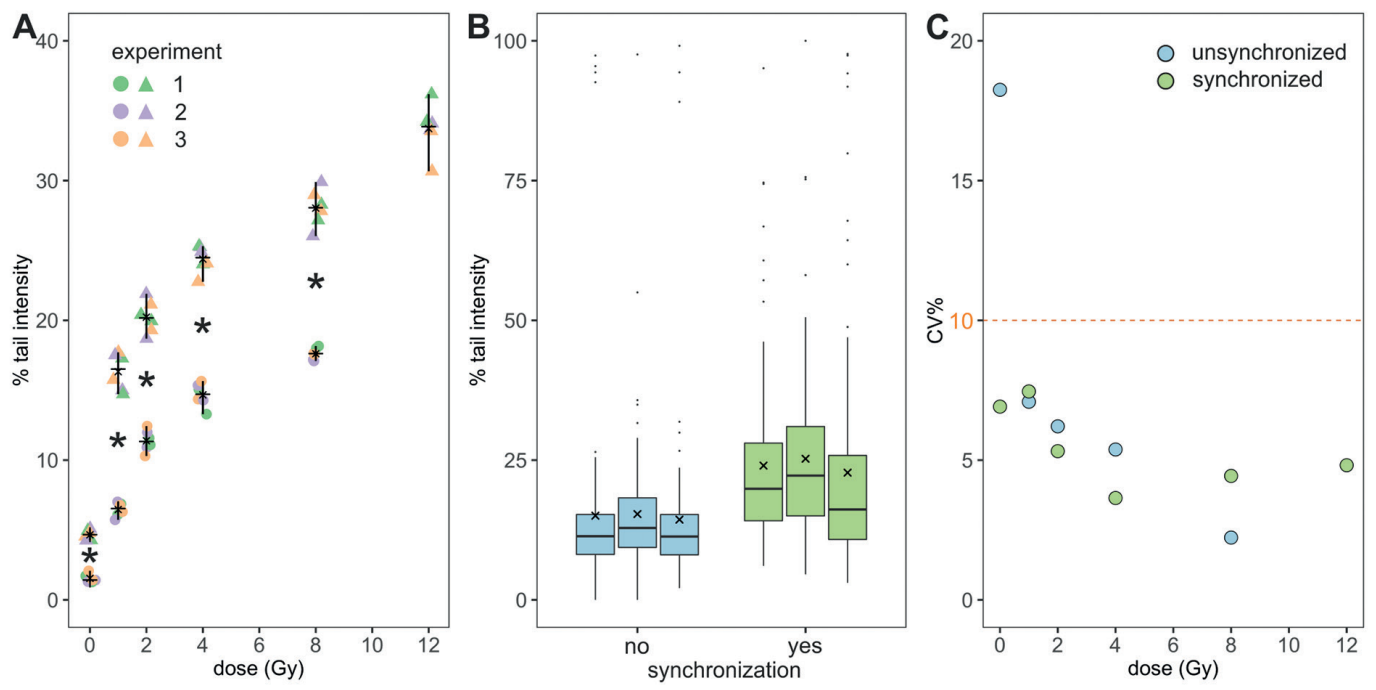

Fig. 4: Synchronization of A549 cells increases susceptibility to x-ray

A) Dose-response curve of unsynchronized (dots) and synchronized (triangles) A549 control cells. Each dot or triangle represents the mean of 100 comets analyzed from one spot. Two spots per experiment were analyzed and are shown in the same color. The mean of all spot means is depicted by a cross $(\mathrm{x})$, the median of all spot means by a horizontal line $(-)$ and the overall spread of all spot means by a vertical line (I). Effects positively correlate with increasing x-ray doses with a correlation coefficient of 0.9 (for non-synchronized as well as synchronized samples). Student's t-test: ${ }^{*} \mathrm{P} \leq 2.5 \times 10^{-6}$ comparing non-synchronized and synchronized samples of the same treatment condition. B) Biological variability of three randomly chosen spots of the 4 Gy-treated unsynchronized (blue) and synchronized (green) sample. Each box contains \% tail intensity values of 100 comets. C) CV values (\%) retrieved from the mean \% tail intensity values of all spots (as shown in A) and the corresponding standard deviations. CV values below $10 \%$ (visualized by the orange dashed line) indicate a sufficient level of reproducibility.

say performance needed to be optimized to maximize the dynamic range of DNA damage detection.

In summary, based on the outcome described above, synchronized A549 cells treated with increasing doses of x-ray were used as the set of control cells for further analysis.

\subsection{Optimization of the assay protocol}

As summarized in Table 1, we varied one parameter at a time while keeping the others constant. Using two of the synchronized cell samples, namely 0 and $4 \mathrm{~Gy}$, we elucidated effects of (1) LMA concentration, (2) temperature of the electrophoresis solution during unwinding and electrophoresis, (3) unwinding time, (4) voltage and (5) electrophoresis time on \% tail intensity values.

In accordance with previous publications (Azqueta et al., 2019; Collins et al., 2014; Azqueta et al., 2011a; Ersson and Moller, 2011; Speit et al., 1999), all modifications affected SCGE results to varying degrees (Fig. 5A, Tab. $\mathrm{S}^{3}$ ). Increasing LMA concentration from 0.4 to $0.68 \%$ led to an unfavorable, though expected, reduction in \% tail intensity values in both the 0 and 4 Gy sample down to 0.9 and $8.4 \%$, respectively. Likewise, both samples were affected by an increase in solution temperature from 4 to $15^{\circ} \mathrm{C}$. The effect was more pronounced in the untreated (0 Gy) sample where $\%$ tail intensity values reached $17 \%$ (an increase by $263 \%$ ). In comparison, values of the 4 Gy sample increased to $30 \%$ tail intensity (an increase by $24 \%$ ). Each of the remaining changes had implications only on the 4 Gy sample. Extending unwinding time from 20 to 40 min increased the \% tail intensity values to $30 \%$. Similarly, an increase in voltage from 1.0 to $1.1 \mathrm{~V} / \mathrm{cm}$ resulted in $\%$ tail intensity values of $26 \%$ and prolonging electrophoresis from 20 to $30 \mathrm{~min}$ in \% tail intensity values of $29 \%$ (Fig. 5 A, Tab. S2 $2^{3}$ ). Variability of all analyzed spots remained low at all conditions examined as indicated by $\mathrm{CV}$ values ranging from $3 \%$ (4 Gy sample) to $15 \%$ (0 Gy sample). One exception at very low $\%$ tail intensity values was observed where the $\mathrm{CV}$ reached $51 \%$ (red dots in Fig. 5A).

In order to maximize the dynamic range of detectable DNA damage, we combined all those parameter changes that elicited an increase in \% tail intensity values in 4 Gy samples while keeping the basal DNA damage in untreated samples reasonably low - preferably around 6\%. Consequently, SCGE was carried out with the following settings: $0.4 \%$ LMA, $4^{\circ} \mathrm{C}, 40$ min unwinding time, $1.1 \mathrm{~V} / \mathrm{cm}$ and $30 \mathrm{~min}$ electrophoresis time, which resulted in $\%$ tail intensity values in 0 and 4 Gy samples of 6.5 and $41 \%$, respectively. Analysis of all (0-12 Gy) synchronized cell samples confirmed a 1.4 (0 Gy) to 1.9 (12 Gy) fold increase in detectable DNA damage values over the whole range of the dose-response 

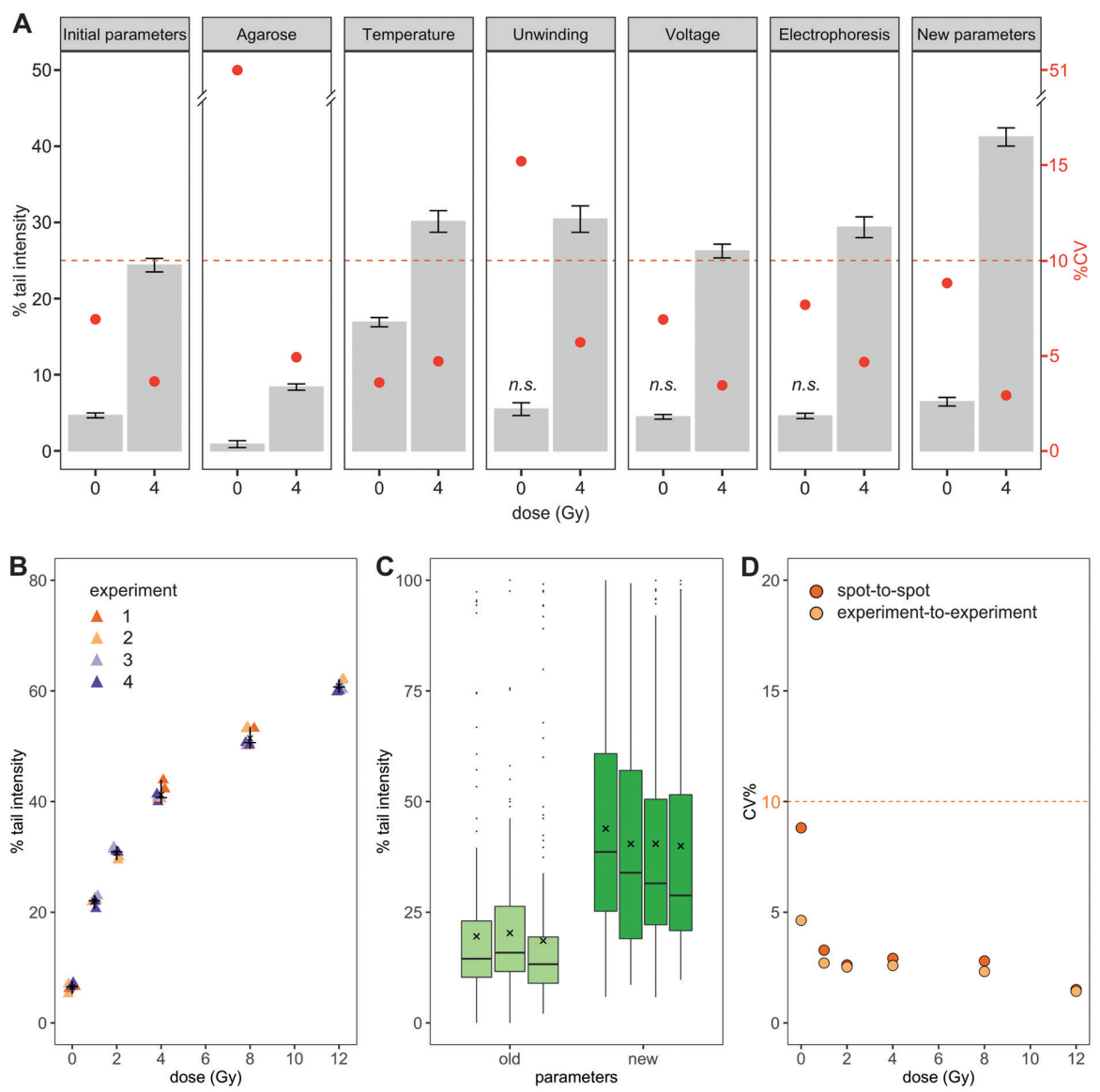

Fig. 5: Optimization of the assay protocol increases the dynamic range of DNA damage detection while keeping variability low A) Untreated ( 0 Gy) and 4 Gy treated synchronized A549 cells were subjected to SCGE. One parameter of assay performance was varied at a time. Grey bars represent mean \% tail intensity values from at least four spots (from two independent experiments) and the corresponding standard deviations. The corresponding CV values (\%) are indicated as red dots; n.s., not significant compared to the 0 Gy sample run with the initial parameters. B) Dose-response curve of the synchronized A549 control cells run with the new assay protocol ( $0.4 \%$ low melting agarose at an electrophoresis solution temperature of $4^{\circ} \mathrm{C}$, with $40 \mathrm{~min}$ unwinding time, $1.1 \mathrm{~V} / \mathrm{cm}$ and 30 min electrophoresis time). Each triangle represents the mean of 100 comets analyzed from one spot. Two spots per experiment were analyzed and are shown in the same color. The effect positively correlates with increasing $x$-ray doses with a correlation coefficient of 0.93 . C) Comparison of the biological variability of three randomly chosen spots of the 4 Gy-treated synchronized sample run with the initial assay protocol (light green) and the new assay protocol (dark green). Each box contains \% tail intensity values of 100 comets (Light green boxes have already been shown in Fig. 4B and are included for easier comparison). D) CV values (\%) retrieved from the mean values of all spots shown in B and the corresponding standard deviations (red dots) as well as retrieved from the experimental means and corresponding standard deviations (yellow dots; for more details please refer to the materials and methods section). CV values below $10 \%$ (visualized by the orange dashed line) indicate a sufficient level of reproducibility.

curve (Fig. 5B). Maximum values in 12 Gy samples reached $60 \%$ tail intensity and are therewith comparable to values reported in literature for x-ray treated TK6 cells (Enciso et al., 2018).

Application of the modified assay parameters even further increased the detectable biological variability within a sample. Box plots visualizing comet distributions from the same 4 Gy-treated synchronized sample run under initial (light green) and modified (dark green) SCGE settings are shown side-by-side in Figure
5C (the full dose-response data are given in Fig. S5 $5^{3}$ ). However, mean and median values retrieved from the same distributions were still reproducible as indicated by consistently low CV values $(<10 \%)$ of experimental as well as spot means (Fig. 5D).

In conclusion, the introduced assay parameter changes increased the dynamic range of DNA damage detection and hence maximized sensitivity while keeping reproducibility at the desired high level. 

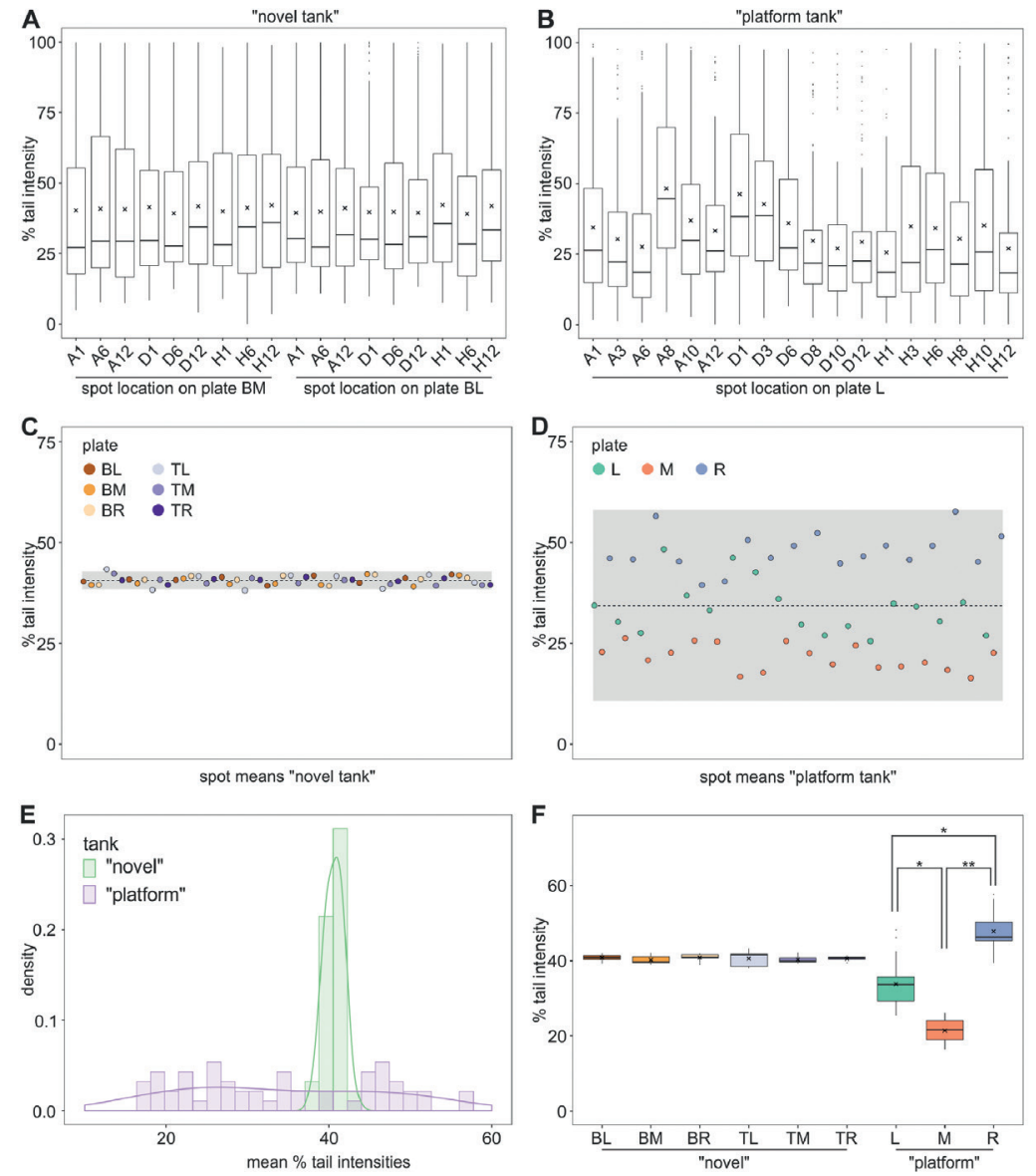

Fig. 6: Improved repeatability of SCGE results in the "novel tank" compared to a standard "platform tank"

In total, 54 spots of the 4 Gy synchronized sample were analyzed in each tank. Six plates with nine spots each or three plates with 18 spots each were run in the "novel" or "platform" tank, respectively. The intrinsic biological variability is visualized as box plots in A and B. 18 spots from plate BM (bottom middle) and $B L$ (bottom left) in the "novel tank" $(A)$ and 18 spots from plate $L$ (left) in the "platform tank" (B) are shown exemplarily. Spot locations on the plate and plate locations in the tanks are indicated on the $x$-axis and correspond with the overview shown in Figure 2. The mean \% tail intensity values of all 54 spots are shown in $\mathrm{C}$ and $\mathrm{D}$. Each dot represents the mean $\%$ tail intensity value of 100 comets from one spot run in the "novel tank" (C) and in the "platform tank" (D). Samples run on the same plate are shown in the same color. The dotted line represents the mean of all spot means. The area marked in grey covers twice the standard deviation derived from all spots analyzed. E) Frequency distribution of all spot means from all plates. F) Each box represents the distribution of the spot means (shown in $C$ and $D$ ) from one plate. Student's t-test: ${ }^{*} P<1.6 \times 10^{-7}$; ${ }^{\star \star} P<1.5 \mathrm{x}$ $10^{-18}$. BL, bottom left; BM, bottom middle; $\mathrm{BR}$, bottom right; TL, top left; TM, top middle; TR, top right; L, left; $M$, middle; $R$, right (plate positions in the respective tanks as shown in Fig. 2).

\subsection{Comprehensive assessment of reproducibility and precision of SCGE in different electrophoresis units}

To elucidate the proportion of variability contributed by electrophoresis, the synchronized cell samples were tested using the optimized assay protocol $\left(0.4 \% \mathrm{LMA}, 4^{\circ} \mathrm{C}, 40 \mathrm{~min}\right.$ unwinding time, $1.1 \mathrm{~V} / \mathrm{cm}, 30 \mathrm{~min}$ electrophoresis time (Tab. 1)) in the controlled electrophoresis settings ("novel tank") in comparison to a standard "platform tank".

As detailed in the materials and methods section above, the "novel tank" is able to run six 96-well format plates simultaneously, while the commercial platform system holds a maximum of three comparable plates. To balance sample numbers, 9 spots and 18 spots of the synchronized 4 Gy sample were spotted per plate of the "novel tank" and the "platform tank", respectively. Spot allocations on the plates and plate positions within the two electrophoresis tanks are shown in Fig. 2A, A', B, B'.

For each system, all spots originated from one vial of cells. Sample preparation was performed identically for both systems, and assay parameters (as elucidated above) were kept as comparable as possible. However, certain constructional differences of the two systems prevented the exact match of all assay parameters. In particular, in the "platform tank", the exact voltage output at the sample could not be monitored during the run and hence was estimated based on prior measurements without samples. Furthermore, the temperature of the electrophoresis solution was not constant for the duration of the run. Measurements after electrophoresis showed an increase in the temperature of the electrophoresis solution from $4^{\circ} \mathrm{C}$ to no more than $11^{\circ} \mathrm{C}$ when operated at the recommended $21 \mathrm{~V}$ and in an air-conditioned $\left(21^{\circ} \mathrm{C}\right)$ laboratory.

Regardless which electrophoresis tank was used, the intrinsic biological variability of the sample was similar. This is exemplarily shown for 18 (out of 54) spots in Fig. 6A ("novel tank") and B ("platform tank") by similarly sized box plots. In contrast, differences in box sizes (i.e., the spread of the comet distribution) from different spots are only apparent in the "platform tank" (Fig. 6B). This variability is also reflected in the mean and 


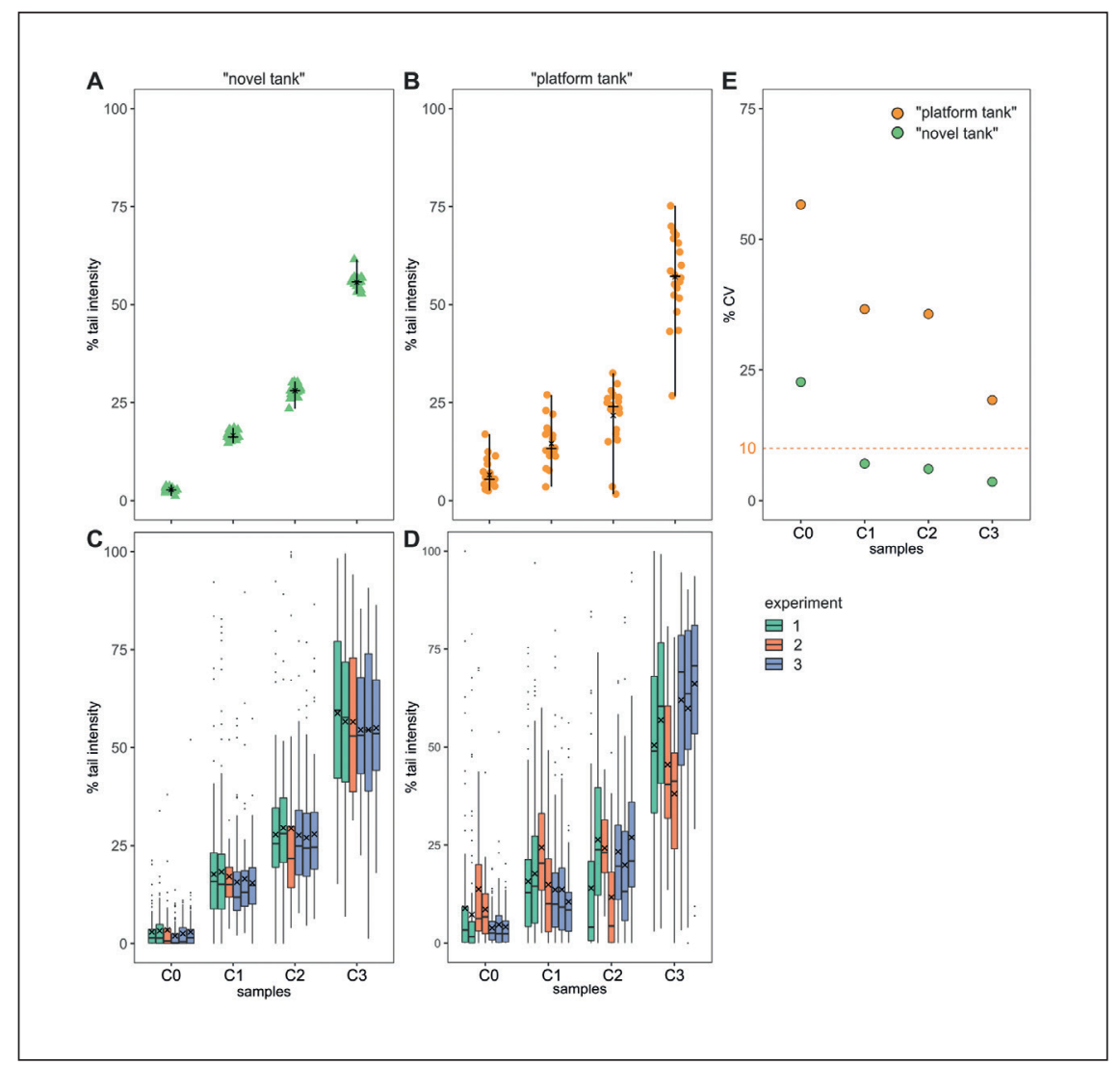

Fig. 7: Control over physical parameters increases reproducibility of results generated in the "novel tank"

Commercially available control cells with increasing DNA damage $(\mathrm{C} 0, \mathrm{C} 1, \mathrm{C} 2$ and C3) were analyzed in the "novel tank" (A, $C)$ and in the "platform tank" (B, D). Each triangle $(A)$ and dot $(B)$ represents the mean $\%$ tail intensity value of one spot. The mean of all spot means is depicted by a cross (x), the median of all spot means by a horizontal line (-), and the overall spread of all spot means by a vertical line (I). The biological variability of the commercial control cell samples is shown in $C$ and $D$ as box plots. Three independent experiments were performed. Spots were distributed over one to three plates. Each box summarizes the $\%$ tail intensities of all comets on one plate. Results from the same experiments are shown in the same color as annotated. E) CV values (\%) retrieved from the mean values of all spots shown in $A$ and the corresponding standard deviations. CV values below $10 \%$ (visualized by the orange dashed line) indicate a sufficient level of reproducibility.

median \% tail intensity values retrieved from these comet distributions. Mean values varied considerably in the "platform tank", ranging from 16 to $57 \%$ (Fig. 6D), but were highly reproducible in the "novel tank", where values spread from 38 to $43 \%$ (Fig. $6 \mathrm{C}$ ). Comparing the mean values from all 54 spots analyzed in each system revealed CV values of $2.8 \%$ and $34.4 \%$ for the "novel" and the "platform" tank, respectively. This 12-fold difference in repeatability and precision within one electrophoretic run and from one spot to the other is also illustrated in the frequency distribution of the same spot mean values from both tanks in Figure $6 \mathrm{E}$. Furthermore, a plate-wise analysis was carried out, where mean $\%$ tail intensity values from spots on individual plates were compared. While the actual position of the plate within the electrophoresis tank (bottom or top, left, middle or right position) did not influence SCGE results in the "novel tank", significant differences were found in the "platform tank" (Fig. 6F).

Since the sample itself as well as the sample preparation and analysis conditions were identical for both tank systems, we can conclude that the increased level of repeatability and precision observed in the "novel tank" results from the strict and accurate control of the physical parameters during electrophoresis.

We recognize that the biological sample as well as the electrophoretic conditions were optimized for use in the "novel tank". Hence, we were curious how "unknown" samples run with the manufacturer's own assay parameters would perform in SCGE. Thus, commercial reference cells (C0: untreated, $\mathrm{C} 1-\mathrm{C} 3$ increas- ing DNA damage) supplied with the "platform tank" were used according to the manufacturer's instructions. Additionally, the corresponding reagent kit was purchased and used for both tank systems. As already detailed above, the parameters of electrophoresis were set as similarly as possible.

Results from three independent experiments are shown in Figure 7A ("novel tank") and B ("platform tank"). For each of the four samples ( $\mathrm{C} 0$ to $\mathrm{C} 3$ ), a total of 18 and 20 spots distributed over 6 and 7 plates were analyzed in the "novel" and "platform tank", respectively. Unfortunately, not all spots contained 100 analyzable comets. Therefore, to depict the intrinsic biological variability of each sample, box plots were generated from all comets on one plate (instead of from all comets in one spot; Figure 7C ("novel tank") and D ("platform tank")). The biological variability of the four samples was similar regardless of the tank used, as indicated by similarly sized box plots (compare Fig. $7 \mathrm{C}$ and D). This is in agreement with results from the 4 Gy synchronized sample. Similarly, the heterogeneity of the comet distributions from one spot to the other was only seen when samples were run in the "platform tank" (Fig. 7D). Mean \% tail intensity values retrieved from the comet distributions of single spots were reproducible in the "novel tank", but showed considerable variability in the "platform tank". The differences in reproducibility are reflected in the $\mathrm{CV}$ values calculated from spot means (Fig. 7E) as well as experimental means (Fig. S6 ${ }^{3}$ ). While CV values achieved in the "novel tank" ranged (on average) from $5.6 \%$ in 
treated samples $(\mathrm{C} 1-\mathrm{C} 3)$ to $23 \%$ in the untreated sample $(\mathrm{C} 0)$, the "platform tank" revealed values of $30.5 \%$ to $57 \%$, respectively. This indicates an improvement in reproducibility by a factor of 2.5 to 5.5 for unknown samples. For all treatment conditions, F-test analysis further confirmed that the variance of all spots was lower in the "novel tank" compared to the "platform tank" and that this difference was statistically significant (Tab. S3 ${ }^{3}$ ).

This becomes obvious when comparing Figure 7A and B: All spot mean values from one treatment condition closely cluster when run in the "novel tank", so that treatment conditions can be easily separated ( $\mathrm{C} 0$ from $\mathrm{C} 1, \mathrm{C} 1$ from $\mathrm{C} 2$, etc.) already by means of the eye. In contrast, spot mean values from the same samples run in the "platform tank" spread considerably and mean $\%$ tail intensity values overlap from one treatment condition to the next, making it difficult to distinguish for example $\mathrm{C} 0$ from $\mathrm{C} 1$, etc.

Nonetheless, when all 18 ("novel tank") or 20 ("platform tank") spot means were considered, t-test analysis revealed a statistically significant difference between the consecutive treatment conditions in both tanks (supplementary file 22: Table 1_data_sets). To assess whether this would also be the case for a more restricted number of spots, we simulated ten times 10,000 experiments with three, four, five and six randomly chosen spot means and performed t-test analysis (supplementary file $2^{2}$ : Tab. 2, 3, 5 and 6). Based on results generated in the "novel tank", three spots sufficed to distinguish $\mathrm{C} 0$ and $\mathrm{C} 1, \mathrm{C} 1$ and $\mathrm{C} 2, \mathrm{C} 2$ and $\mathrm{C} 3$ in at least $99.99 \%$ of all simulated cases with statistical significance on a $95 \%$ confidence interval. In contrast, results from the "platform tank" allowed for a significant discrimination between $\mathrm{C} 0$ and $\mathrm{C} 1$ in $27 \%$ of all cases, between $\mathrm{C} 1$ and $\mathrm{C} 2$ in $21 \%$ and between $\mathrm{C} 2$ and $\mathrm{C} 3$ in $82 \%$. More stringent analysis on a $99 \%$ confidence interval revealed for three spots of the "novel tank" that $\mathrm{C} 0$ and $\mathrm{C} 1$ could still be distinguished in $100 \%$ of the cases, $\mathrm{C} 1$ and $\mathrm{C} 2$ in $86 \%$ and $\mathrm{C} 2$ and $\mathrm{C} 3$ in $99.9 \%$ of all cases. Under these conditions, results from the "platform tank" allowed to discriminate between $\mathrm{C} 0$ and $\mathrm{C} 1$ as well as between $\mathrm{C} 1$ and $\mathrm{C} 2$ in only $7 \%$ of all cases and between C2 and C3 in 39\% of all cases. Increasing the spot number from the "platform tank" to six revealed significant differences between $\mathrm{C} 0$ and $\mathrm{C} 1$ in $38 \%$ of all cases, between $\mathrm{C} 1$ and $\mathrm{C} 2$ in $22 \%$ and between $\mathrm{C} 2$ and $\mathrm{C} 3$ in $99.6 \%$. In contrast, four spots from the "novel tank" were enough to discriminate between consecutive treatment conditions in $100 \%$ of all cases. For this particular data set, our findings imply on average a three-fold or nine-fold increase in selectivity for the "novel tank" when three spots are analyzed on a 95 or $99 \%$ confidence interval, respectively.

This preliminary analysis indicates that the increase in repeatability and reproducibility finally reduces the number of spots needed to distinguish between different treatment conditions in a reliable manner.

\section{Discussion}

In how far would a "perfect electrophoresis tank system" enable the use of SCGE in biomonitoring and diagnostics or precision health care?
To tackle this important question, we kept three of four known sources of SCGE variability constant, namely the biological sample, the assay protocol and the analysis procedure (shown in Fig. 1 in red). Thereby the impact of electrophoresis on SCGE results (shown in Fig. 1 in green) could be systematically assessed in a "novel tank" and benchmarked against a commercially available standard "platform tank".

For generation of the set of control cells, we chose increasing doses of x-ray irradiation and the A549 cell line. As expected (McArt et al., 2010), synchronization of A549 cells in S-phase increased the cells' susceptibility to x-ray treatment. However, rather unexpectedly, we observed a simultaneous increase in the intrinsic biological variability. This was associated with a certain risk for the project's task, since overall assay variability is supposed to be the sum of all sources of variability, including also the intrinsic variability of the biological sample (see introduction for more details). On the other hand, "real" biological samples such as tissue biopsies or blood samples also possess a certain unknown intrinsic variability that might be even higher compared to our control cells. Using control samples with such an intrinsic distribution rather than a "perfect" control sample with artificially low intrinsic variability increases the meaningfulness and applicability of our results for "real life" samples.

Having generated a sufficiently large batch of these cells allowed us to keep the variability constant for the whole duration of the study. With a customized assay protocol for this particular set of samples, we cover a reasonable dynamic range of DNA damage detection with the "novel tank". In contrast to OECD recommendations (OECD, 2016), this assay protocol uses a final LMA concentration of $0.4 \%$. We demonstrate that sensitivity increases with reduced LMA concentration. Conversely, higher LMA concentrations mask the detection of higher DNA damage levels (Fig. 5). While low LMA percentages have been reported to result in rather fragile gels (Azqueta et al., 2011b, 2019; Gutzkow et al., 2013), no detachments of spots at any time during the experiments was observed over the entire study duration. Taking these facts together justifies the deviation from the OECD TG and is further in line with findings by Collins and co-workers (2014), who showed that agarose concentration is one of the major contributors to variation in assay results.

Using the synchronized control cells and the "novel tank", we show that even samples with a high intrinsic variability on the single cell/comet level can be analyzed with high precision and repeatability. Mean \% tail intensity values of 54 spots of the same 4 Gy sample vary significantly less in the "novel tank" compared to results from the "platform tank" (Fig. 6). This indicates that accurate control over physical parameters during electrophoresis is key to achieving reproducible SCGE results. This was further confirmed using a commercially available control set including cells, protocol and equipment from the same manufacturer (standard "platform tank"; Fig. 7). Reproducibility from one spot to the other and even from one experiment to the other was significantly better in the "novel tank" as compared to the "platform tank".

We could further demonstrate that for this particular data set fewer technical replicates (i.e., spots) were needed to distinguish between samples of different DNA damage levels. Com- 
paring three spots (as recommended in the OECD TG) revealed an up to nine-fold increase in selectivity for data generated in the "novel tank". Such a level of significance could not be reached in a standard "platform tank", even with increasing spot numbers. This is of particular relevance for SCGE applications in diagnostics and biomonitoring for two reasons. On the one hand, it implies a potential reduction of biological material needed from patient biopsies, which is often of limited availability. Similarly, valuable material from animal tissues can be used most efficiently, making the most out of each animal experiment. On the other hand, and even more importantly, the reduced assay variability might change the conclusion of Forchhammer and colleagues (2010): They regard the SCGE assay as a suitable method to detect biological differences between two populations. However, they considered assay variation as too high for diagnostic purposes or for the estimation of possible disease risks. With accurate control over electrophoresis parameters, we provide a technical solution to reduce variation in SCGE to a level where finally a distinction between treated and untreated samples or samples of healthy and diseased origin might be feasible. Therefore, to show the general validity of the results presented here, further analyses with diverse sets of samples in inter-laboratory trials are needed. This will pave the way for the application of SCGE as part of a high-throughput strategy in medical diagnostics and biomonitoring.

There is indeed huge potential to use SCGE as a diagnostic tool for cancer, in liquid biopsies and chemical safety (Anderson et al., 2013, 2014). The European Food Safety Association (EFSA) and the European Chemicals Agency (ECHA) have listed SCGE as an appropriate genotoxicity test (ECHA, 2018; EFSA, 2012), which satisfies several requirements listed by the EC Regulation on chemicals and their safe use (REACH). Furthermore, application of SCGE for human biomonitoring of environmental, occupational or lifestyle chemicals (Anderson et al., 2013; Azqueta et al., 2019; Davison, 2016; Koppen et al., 2018) and in the improvement of cancer diagnostics and therapy are ongoing (Anderson et al., 2014, 2019; Apostolou et al., 2014; Buchynska et al., 2017; Dandah et al., 2018).

Besides the demonstrated precision, further factors need to be combined in order to enable the routine use of SCGE technology. These include the ease of sample handling and HT capabilities from sample preparation until analysis. There have been several attempts to produce fast HT SCGE assays, but these studies have only addressed the speed of the assay, neglecting the reproducibility by not addressing the factors that lead to variation in SCGE (Stang and Witte, 2009; Wood et al., 2010). Furthermore, the technical complexity of some SCGE assays, such as the application of microtiter wells, may further prevent the routine application of the technology (Stang and Witte, 2009). The particular 96-well format plates used with the "novel tank" allow a simple, fast and robust sample preparation. This is highlighted by the fact that even $0.4 \%$ LMA gels can easily be used without any risk of detachment. In combination with the "novel tank" which runs six of these 96-well format plates at a time on customized programs, this ensures a fast and standardized assay procedure until the end of the electrophoresis. From personal ex- perience, we estimate that the experimental hands-on time for a standard genotoxicity test according to OECD TG 489 could be reduced from nine to three hours. This excludes scoring and analysis time, which has not been addressed in this study.

A robust and reliable analysis solution is another important factor for precision as well as HT capability, and additional efforts will need to be invested to realize this. Sample analysis is responsible for most of the observed inter-laboratory variability of SCGE (Collins et al., 2014; Forchhammer et al., 2010). In the present study, images were analyzed by a single operator using one semi-automated software and according to a defined protocol. While such a "pragmatic" strategy worked nicely to minimize intra-laboratory variability, it is certainly useless for tackling inter-laboratory issues of reproducibility and comparability. Therefore, an automated, reliable, easy-to-handle, user-friendly and affordable analysis solution that is able to process diverse image file formats is urgently needed - especially considering the high-throughput aspect of being able to run six 96-well format plates simultaneously (576 spots). The currently available and commonly used manual or semi-automated analysis software solutions such as CometAssayIV (Perceptive Instruments) and Lucia (Lucia cytogenics), although specific for SCGE, are obviously not optimal for HT application. Furthermore, operator-dependent variations constitute a known drawback (Forchhammer et al., 2010). Automated systems may offer several advantages such as speed, but, more importantly, can also avoid operator-dependent bias. Imstar Pathfinder ${ }^{\mathrm{TM}}$ is reported to analyze 96-well format minigels in under $4 \mathrm{~h}$ (Brunborg et al., 2014). MetaSystems CometImager system automatically determines the best plane of focus at each captured field and scores comets only if several outlined conditions are met (Stang et al., 2010). However, special costly equipment is needed in both cases. Open platforms such as CASPLab, CellProfiler and OpenComet (ImageJ plug-in) exist but still require further development. Manual editing of results is still necessary, which is time consuming and can also introduce human error variability caused by user-to-user differences.

\section{Conclusion}

Using a novel electrophoresis tank in comparison to a standard platform electrophoresis tank, we show that control over the physical parameters is a key requirement to increase SCGE repeatability, reproducibility and precision, irrespective of the intrinsic biological variability of the sample. Optimum standardized assay protocols are essential to cover a reasonable dynamic range and may vary with respect to the biological sample of interest. Furthermore, our results show that following such a strict and optimized SOP increases reproducibility but solely in combination with controlled electrophoresis conditions. The high-throughput electrophoresis solution presented here solves one of the key issues of SCGE variability. The achieved precision together with a reduction in required sample number and processing time on an HT level will not only decrease costs but also facilitate the application of SCGE for diagnostic purposes. 
In the near future, the combination with reliable automated acquisition and analysis software solutions will offer a precise and reproducible HT SCGE platform for the generation of new prognostic outputs.

\section{References}

Anderson, D., Dhawan, A. and Laubenthal, J. (2013). The comet assay in human biomonitoring. Methods Mol Biol 1044, 347362. doi:10.1007/978-1-62703-529-3_18

Anderson, D., Najafzadeh, M., Gopalan, R. et al. (2014). Sensitivity and specificity of the empirical lymphocyte genome sensitivity (LGS) assay: Implications for improving cancer diagnostics. FASEB J 28, 4563-4570. doi:10.1096/fj.14-254748

Anderson, D., Najafzadeh, M., Scally, A. et al. (2019). Using a modified lymphocyte genome sensitivity (LGS) test or tumorscan test to detect cancer at an early stage in each individual. FASEB BioAdvances 1, 32-39. doi:10.1096/fba.1020

Apostolou, P., Toloudi, M., Kourtidou, E. et al. (2014). Use of the comet assay technique for quick and reliable prediction of in vitro response to chemotherapeutics in breast and colon cancer. J Biol Res (Thessalon) 21, 14. doi:10.1186/2241-5793-2114

Azqueta, A., Gutzkow, K. B., Brunborg, G. et al. (2011a). Towards a more reliable comet assay: Optimising agarose concentration, unwinding time and electrophoresis conditions. Mutat Res 724, 41-45. doi:10.1016/j.mrgentox.2011.05.010

Azqueta, A., Meier, S., Priestley, C. et al. (2011b). The influence of scoring method on variability in results obtained with the comet assay. Mutagenesis 26, 393-399. doi:10.1093/mutage/ geq105

Azqueta, A., Muruzabal, D., Boutet-Robinet, E. et al. (2019). Technical recommendations to perform the alkaline standard and enzyme-modified comet assay in human biomonitoring studies. Mutat Res Genet Toxicol Environ Mutagen 843, 24-32. doi:10.1016/j.mrgentox.2019.04.007

Brunborg, G., Jackson, P., Shaposhnikov, S. et al. (2014). High throughput sample processing and automated scoring. Front Genet 5, 373. doi:10.3389/fgene.2014.00373

Brunborg, G., Rolstadaas, L. and Gutzkow, K. B. (2018). Electrophoresis in the comet assay. In O.-M. Boldura and C. Balta (eds.), Electrophoresis - Life Sciences Practical Applications. doi:10.5772/intechopen.76880

Buchynska, L. G., Brieieva, O. V., Iurchenko, N. P. et al. (2017). DNA damage in tumor cells and peripheral blood lymphocytes of endometrial cancer patients assessed by the comet assay. Exp Oncol 39, 299-303. doi:10.31768/2312-8852.2017.39(4):299303

Collins, A. (2004). The comet assay for DNA damage and repair: Principles, applications, and limitations. Mol Biotechnol 26, 249-261. doi:10.1385/mb:26:3:249

Collins, A. R., El Yamani, N., Lorenzo, Y. et al. (2014). Controlling variation in the comet assay. Front Genet 5, 359. doi:10.3389/fgene.2014.00359

Dandah, O., Najafzadeh, M., Isreb, M. et al. (2018). Aspirin and ibuprofen, in bulk and nanoforms: Effects on DNA dama- ge in peripheral lymphocytes from breast cancer patients and healthy individuals. Mutat Res Genet Toxicol Environ Mutagen 826, 41-46. doi:10.1016/j.mrgentox.2017.12.001

Davison, G. W. (2016). Exercise and oxidative damage in nucleoid DNA quantified using single cell gel electrophoresis: Present and future application. Front Physiol 7, 249. doi:10.3389/ fphys.2016.00249

ECHA (2018). Three recently approved in vivo genotoxicity test guidelines. https://echa.europa.eu/documents/ 10162/21650280/oecd_test_guidelines_genotoxicity_en.pdf/ 56ab5788-0103-4716-8903-59ab0c942efe

EFSA (2012). Minimum criteria for the acceptance of in vivo alkaline comet assay reports. EFSA J 10, 12. doi:10.2903/j.efsa. 2012.2977

Enciso, J. M., Gutzkow, K. B., Brunborg, G. et al. (2018). Standardisation of the in vitro comet assay: Influence of lysis time and lysis solution composition on the detection of DNA damage induced by x-rays. Mutagenesis 33, 25-30. doi:10.1093/ mutage/gex039

Ersson, C. and Moller, L. (2011). The effects on DNA migration of altering parameters in the comet assay protocol such as agarose density, electrophoresis conditions and durations of the enzyme or the alkaline treatments. Mutagenesis 26, 689-695. doi:10.1093/mutage/ger034

Forchhammer, L., Johansson, C., Loft, S. et al. (2010). Variation in the measurement of DNA damage by comet assay measured by the ecvag inter-laboratory validation trial. Mutagenesis 25 , 113-123. doi:10.1093/mutage/gep048

Forchhammer, L., Ersson, C., Loft, S. et al. (2012). Inter-laboratory variation in DNA damage using a standard comet assay protocol. Mutagenesis 27, 665-672. doi:10.1093/mutage/ ges032

Gutzkow, K. B., Langleite, T. M., Meier, S. et al. (2013). Highthroughput comet assay using 96 minigels. Mutagenesis 28, 333-340. doi:10.1093/mutage/get012

Henderson, L., Wolfreys, A., Fedyk, J. et al. (1998). The ability of the comet assay to discriminate between genotoxins and cytotoxins. Mutagenesis 13, 89-94. doi:10.1093/mutage/13.1.89

Hirsch, C., Kaiser, J. P., Wessling, F. et al. (2011). A novel comprehensive evaluation platform to assess nanoparticle toxicityin vitro. J Phys Conf Ser 304. doi:10.1088/1742-6596/ 304/1/012053

Koppen, G., De Prins, S., Jacobs, A. et al. (2018). The comet assay in human biomonitoring: Cryopreservation of whole blood and comparison with isolated mononuclear cells. Mutagenesis 33, 41-47. doi:10.1093/mutage/gex034

May, S., Hirsch, C., Rippl, A. et al. (2018). Transient DNA damage following exposure to gold nanoparticles. Nanoscale 10, 15723-15735. doi:10.1039/c8nr03612h

McArt, D. G., McKerr, G., Saetzler, K. et al. (2010). Comet sensitivity in assessing DNA damage and repair in different cell cycle stages. Mutagenesis 25, 299-303. doi:10.1093/mutage/ geq006

Moller, P., Loft, S., Ersson, C. et al. (2014). On the search for an intelligible comet assay descriptor. Front Genet 5, 217. doi:10. 3389/fgene.2014.00217 
OECD (2016). Test No. 489: In Vivo Mammalian Alkaline Comet Assay. OECD Guidelines for the Testing of Chemicals, Section 4. OECD Publishing, Paris. doi:10.1787/9789264264885en

Olive, P. L., Wlodek, D., Durand, R. E. et al. (1992). Factors influencing DNA migration from individual cells subjected to gel electrophoresis. Exp Cell Res 198, 259-267. doi:10.1016/00144827(92)90378-1

Ostling, O. and Johanson, K. J. (1984). Microelectrophoretic study of radiation-induced DNA damages in individual mammalian cells. Biochem Biophys Res Commun 123, 291-298. doi:10.1016/0006-291x(84)90411-x

Pedrali-Noy, G., Spadari, S., Miller-Faures, A. et al. (1980). Synchronization of hela cell cultures by inhibition of DNA polymerase alpha with aphidicolin. Nucleic Acids Res 8, 377-387. doi:10.1093/nar/8.2.377

Potter, A. J., Gollahon, K. A., Palanca, B. J. et al. (2002). Flow cytometric analysis of the cell cycle phase specificity of DNA damage induced by radiation, hydrogen peroxide and doxorubicin. Carcinogenesis 23, 389-401. doi:10.1093/carcin/ 23.3.389

Singh, N. P., Mccoy, M. T., Tice, R. R. et al. (1988). A simple technique for quantitation of low-levels of DNA damage in individual cells. Exp Cell Res 175, 184-191. doi:10.1016/00144827(88)90265-0

Sirota, N. P., Zhanataev, A. K., Kuznetsova, E. A. et al. (2014). Some causes of inter-laboratory variation in the results of comet assay. Mutat Res Genet Toxicol Environ Mutagen 770, 1622. doi:10.1016/j.mrgentox.2014.05.003

Speit, G., Trenz, K., Schutz, P. et al. (1999). The influence of temperature during alkaline treatment and electrophoresis on results obtained with the comet assay. Toxicol Lett 110, 73-78. doi:10.1016/s0378-4274(99)00137-x

Stang, A. and Witte, I. (2009). Performance of the comet assay in a high-throughput version. Mutat Res 675, 5-10. doi:10.1016/j. mrgentox.2009.01.007
Stang, A., Brendamour, M., Schunck, C. et al. (2010). Automated analysis of DNA damage in the high-throughput version of the comet assay. Mutat Res 698, 1-5. doi:10.1016/j.mrgentox. 2010.02.014

Wood, D. K., Weingeist, D. M., Bhatia, S. N. et al. (2010). Single cell trapping and DNA damage analysis using microwell arrays. Proc Natl Acad Sci U S A 107, 10008-10013. doi:10.1073/pnas.1004056107

\section{Conflict of interest}

The work presented here was funded by the Commission of Technology and Innovation (CTI number 18535.1 PFLS-LS), indicating that half of the project was financed by the industrial partner (4D Lifetec AG) and half was financed by the Swiss federal state.

\section{Author contribution}

OS was responsible for the development and manufacturing of the novel electrophoresis tank. JCC and $\mathrm{CH}$ carried out the experiments, analyzed the data, and wrote the manuscript with support from $\mathrm{PW}$ and $\mathrm{CH}$, who were both involved in supervising and structuring of the project. MR assisted with analysis of data and statistical interpretation. TL and RK performed irradiation of samples. All authors contributed to revising the manuscript.

\section{Acknowledgments}

The work was funded by the Commission of Technology and Innovation, Bern, Switzerland (CTI number 18535.1 PFLS-LS). The authors would like to acknowledge Dr Markus Rottmar and Ms. Stefanie Guimond for their help in image acquisition. Special thanks go to Ms. Nadine Bramaz from the UTOX lab at EAWAG (Duebendorf, Switzerland) for hosting our cells before and after X-ray treatment. 